\title{
CLASSICS IN SOUTH AFRICA-A WAY FORWARD'
}

\author{
E A Mackay (University of Natal, Durban)
}

Sometimes there is a certain rightness in the timing of things. When it was agreed two years ago that "Change and Continuity in the Ancient World" would be the theme for this conference, it was perceived as appropriate to the millennium; we did not then foresee that it would, with a slight rewording, become something of a rallying cry: "Change, and Continuity of the Ancient World." Then, two years ago also, we accepted the offer of the University of the Western Cape as a hosting venue. It seemed wryly appropriate at the time, as a campus that had long been vigorously associated with the desire for change rather than continuity of the older order. I wonder how many of you have now observed the University's motto: respice prospice: Look back, look forward. This is highly appropriate to our chosen theme, and appropriate too to the situation in which we find ourselves. It is perhaps most appropriate of all to the timing of this conference and of our crisis, at the end of a millennium when indeed everyone feels a need to look back in assessment of what has passed, to look forward and to try to plan for the future.

The Chairperson's Address has at past meetings generally tended to present a piece of academic research. On this occasion, although I would have enjoyed regaling you with some of my recent archaeological observations-with new wine from old amphorae, so to speak-it seems infinitely more relevant, and potentially more useful, to offer some consideration of the situation in which Classics finds itself now in South Africa, and to seek a way forward for our discipline that can preserve its integrity while at the same time serving a wider community than we have done hitherto. For my address, the theme of the conference could not have been more apt, for in paper after paper, we have been presented with evidence of the chameleon character of the Classics, and of the dynamic tension that persisted through the history, philosophy, art and literature of a thousand years of antiquity - and is still, 2000 years later, inculcated in those that study them deeply-between reverence for mos maiorum and a perpetual enthusiasm for res novae.

\section{The Status Quo}

In this spirit, then, I shall present first an overview of the situation in the Departments of Classics around the country, and shall then proceed with some suggestions of how we may be able to improve our position. You will probably each find some of them extreme, others not to your liking, and you will surely feel that I have overlooked some that are to you self-evident: I do not plan to prate for the whole two hours

I This paper is an edited version of the Chairperson's Address to the 23rd Biennial Meeting of the Classical Association of South Africa, University of the Western Cape, Bellville, January 1999. In the time between delivery and publication it has been up-dated to reflect registration and staff statistics for 1999 instead of the 1998 figures originally discussed, in the interests of providing as immediate an evaluation as possible of the situation of Classics in South Africa. 
allotted to this session, but rather to try to stimulate an open discussion from which some firm policies for the future should emerge.

Table 1 (pp.82-83) presents a breakdown of the current staff and student situation ${ }^{2}$ in those Departments around the country that are still offering Classics, ${ }^{3}$ in comparison with the figures for 1994: in each case the 1994 figure is given first, separated by a dash from the 1999 figure, except where only 1999 figures were provided. The formula (0) marks cases where a course has been introduced since 1994, or where a course has been discontinued before 1999. For comparative purposes, semesterised figures have been expressed as year equivalents. ${ }^{4}$

The massive drop in Latin I across the spectrum results from the abolition of the Latin requirement for law practice from 1995. Numbers for Greek I tend to be low except at those universities where Theology is offered; it is a little disturbing that even there, numbers in some courses have tended to drop significantly, perhaps reflecting a corresponding drop in Theology registrations. The introduction of a full suite of courses in Modern Greek at RAU has clearly been a success, although this must be off-set against the associated increase in staff, since four part-time lecturers teach Modern Greek only. The second and third years of both ancient Greek and Latin, while very low, do not on the whole show significant change over the past six years. At the post-graduate level again, the variations are not really statistically significant. It is more worrying to find reductions in the Classical Civilisation and Ancient History blocks, especially in first year, for these should be the courses that appeal most readily to students, where we can compete more or less equally with disciplines such as English, History, and Philosophy: here is where we need to concentrate our efforts.

Overall, the trend as regards decreasing numbers is predictable: the languages are the most affected, and where numbers have always been small they tend to be shrinking a little more, while where they have been large (apart from Latin) they are

2 For the publication of this paper late in 1999, the figures in the table have been up-dated from the time when this paper was delivered to reflect current registrations in 1999; I should like to thank the following colleagues for providing me with the statistical information: Dr M R Dircksen (PUK), Prof B Hendrickx (RAU), Mr W Snowball (RU), Prof J E Atkinson (UCT), Prof L Cilliers and Prof J V Cronjé (UFS), Dr R J Evans (UNISA), Prof D L Pike (UNP) Prof J H Barkhuizen (UP), Dr J C Zietsman (US), Dr B van Zyl-Smit (UWC), Prof S Farron (Wits); for abbreviations of the university names, please refer to the note appended to the table.

3 For some universities it has not proved possible to obtain detailed information: the University of Durban-Westville closed its Department of Classics from 1998, and its Department of Theology will have phased out New Testament Greek before 2001; the University of Fort Hare closed its Classics Department at the end of 1998, but its Department of New Testament and Classical Theology still teaches Classical Greek, New Testament Greek, and Classical Culture; the University of the North retains its Department of Classical Languages; the University of Port Elizabeth ceased to offer Classics courses at the end of 1998, as did the University of Transkei from 1997; the University of Zululand closed its Classics Department from 1992, but its Department of Theology still offers New Testament Greek, and may perhaps offer a module in Latin in 2000. No information is available on the University of Venda.

4 That is, a first-semester course with 150 students followed by a second-semester course with 120 is recorded as 135 . 
dropping quite dramatically by around $25 \%$ or more. This is extremely disquieting, for as many of us have cause to know, university administrators deal in quantifiable, not qualitative, criteria, and so jobs are being placed on the line. We all know that the loss of students can be due to quite a number of diverse factors, and I am sure that many of you feel that you have been more committed, better prepared, more charismatic, even, in your teaching than colleagues in other, less vulnerable, disciplines, which of course makes it all the more depressing, when one is doing one's utmost in every respect and still being "counted out". We have to accept that in the medium term the continuation of our discipline-and our jobs-cannot now depend on our mounting of the traditional courses in ancient Greek and Latin, no matter how skilfully and enticingly we do so.

Now let us look at those parts of the table where a more optimistic picture is presented. Apart from Modern Greek, these are to be found in Classical Civilisation, particularly at UCT (where the restructuring of courses at different levels at first glance obscures the overall increase from 78 to 90), UND and US. In Durban, the 92 relates to 184 students taking a semester-course in medical etymology and medical history with some ethics from Philosophy, set up by Classics staff for the Medical School; the biggest increase is generated by the popularity of the first-year semester course Words and Ideas, which is leading in turn to rising registrations in the more senior courses. In Stellenbosch the proportion of students continuing from a very large first year into second year has risen from $19 \%$ to $54 \%$.

In these courses, something is working well, and it makes sense for us all to consider what that may be, and to learn from it. Our future and the future of our discipline will depend on how far we are prepared to cooperate and collaborate on a national scale. I shall be inviting those Departments with significant increases to comment on reasons for their success in the discussion that will follow this address; in my experience it is not only charismatic teaching or innovative syllabi that make the difference (although these are always an advantage), but other factors that are likely to be beyond our direct control, such as a supportive faculty.

What I have said so far may sound like a suggestion that student numbers are all that matter. This is far from my position, for pragmatic as well as ethical reasons: if we are perceived to be lowering our academic standards in an attempt to lure hordes of mark-hungry students into our courses, our jealous detractors are thereby provided with another stick with which to beat us. Our courses must be popular for the right reasons. I shall return to this point later, for it is a vital concern.

Finally, it is clear from the staffing section of Table 1 that falling student numbers have already led to reductions in the teaching staff in many departments. ${ }^{5}$

5 Some figures need explanation: the increase in RAU staff from 9 to 11 is related to the increase in Modern Greek; the increasing part-time figure for UND is excluded from the total as this records graduate student temporary tutors involved only in the large first-year courses; the UNP total of 3.16 reflects partial redeployment of several staff to other disciplines; the Wits total of 2.5 reflects one staff-member's shift to a part-time position. 


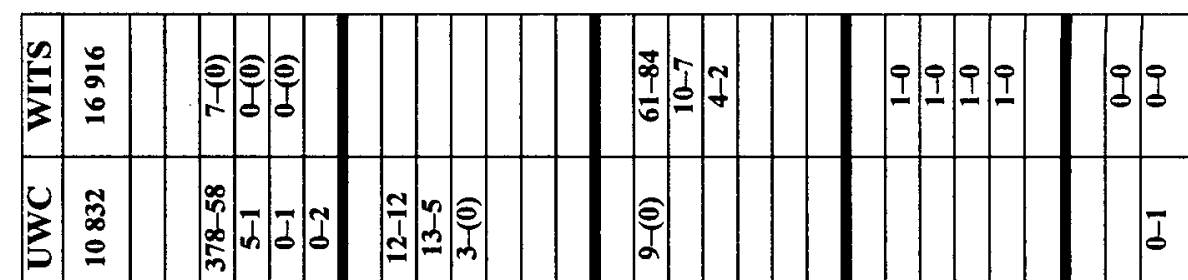

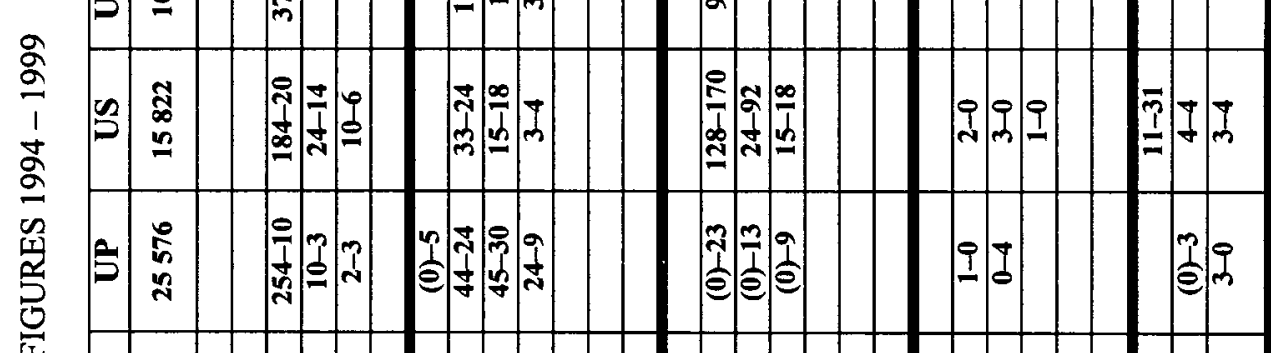

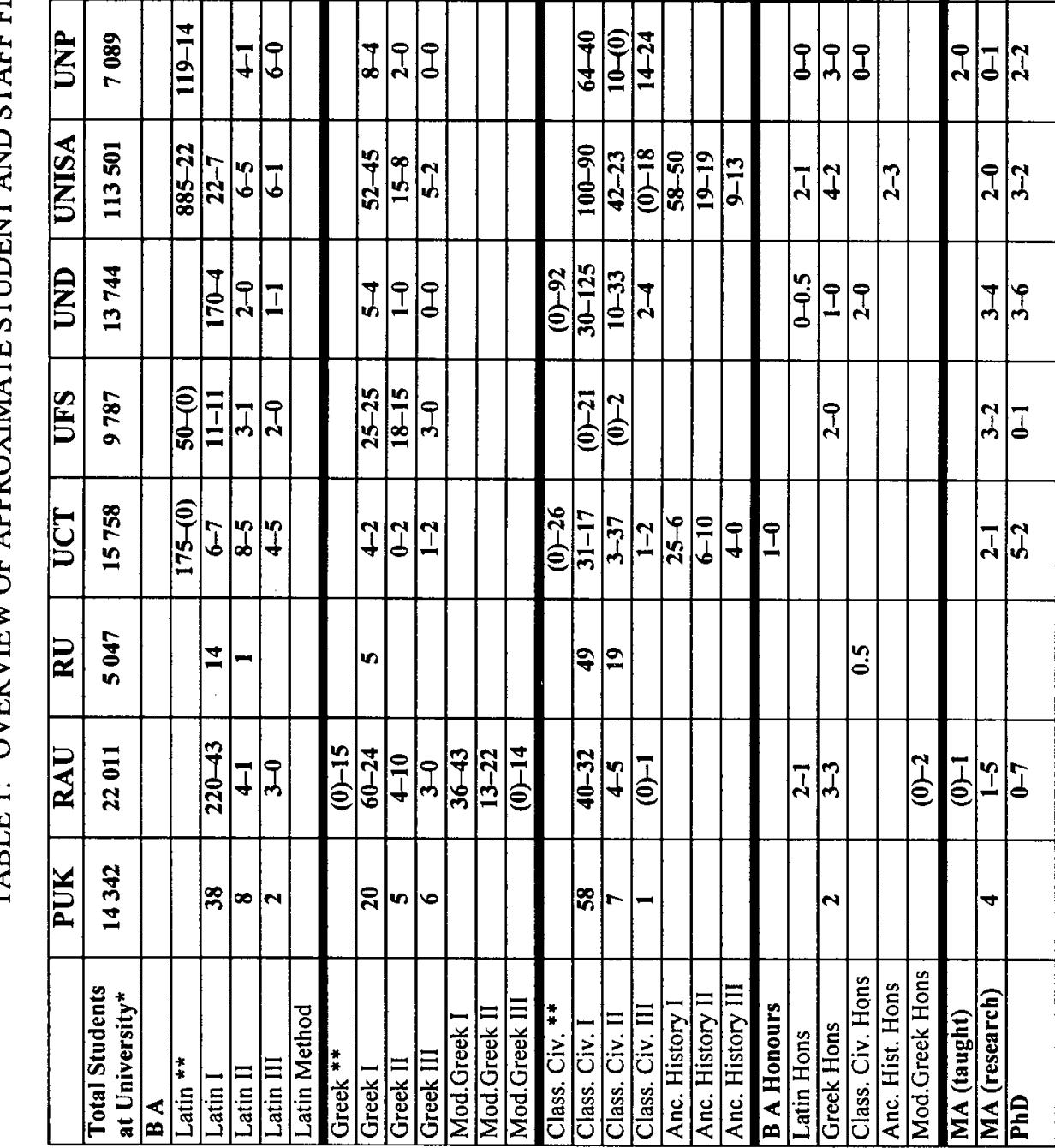




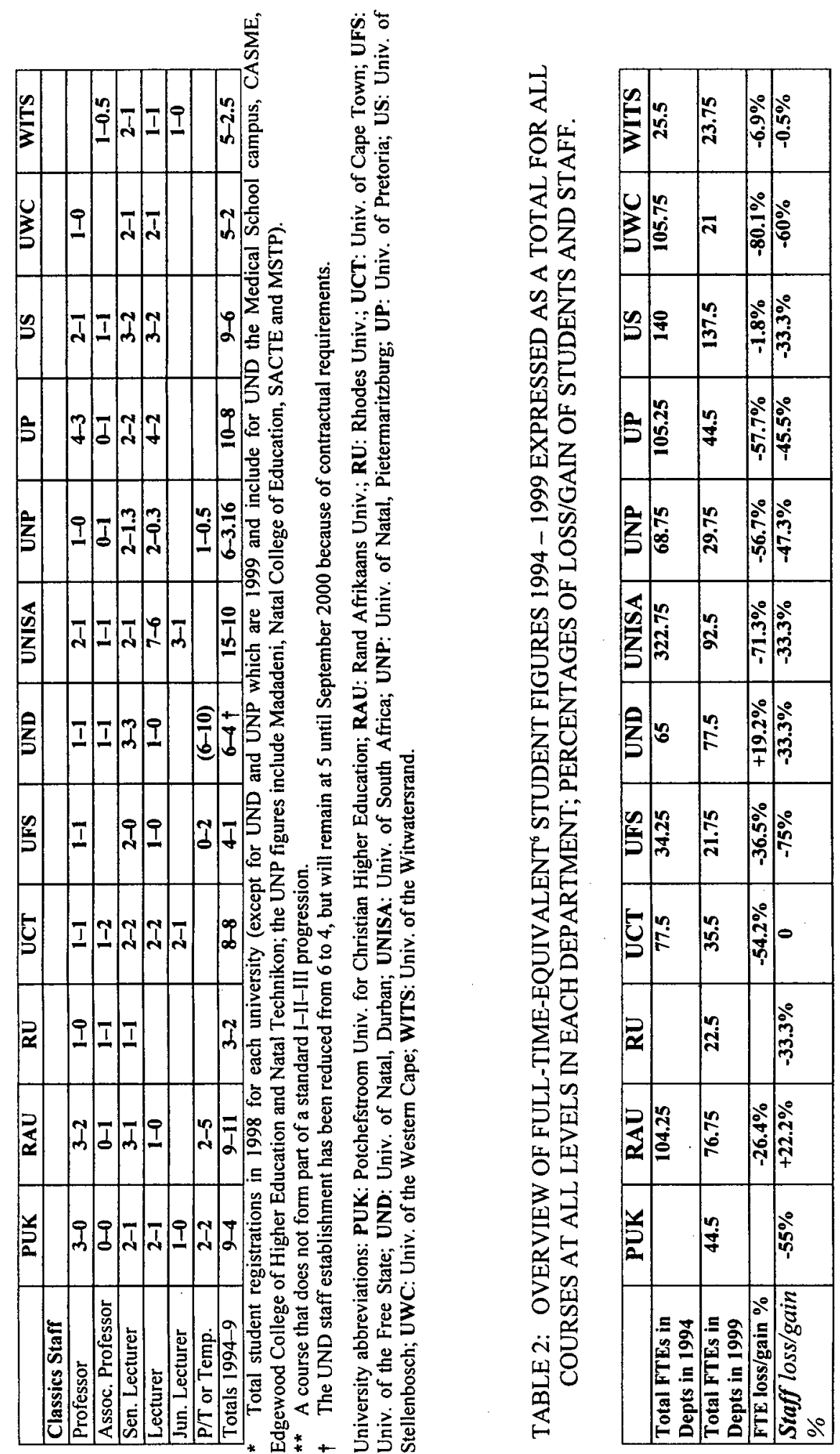

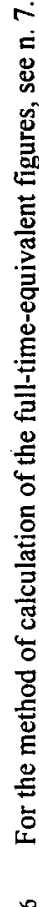


Table 2 (p.83) records the percentage loss or gain in terms of "full-time-equivalent" registration figures, ${ }^{7}$ expressing the 1999 number as a percentage of the 1994 number; the staffing losses or gains are similarly expressed. Comparison of these sets of figures reveals the arbitrary nature of the individual universities' rationalisation and restructuring procedures. Inter-university consultation on a national level should surely have been undertaken from the outset.

\section{A Way Forward}

The corollary to my earlier comment about being unable to depend on the languages for the future is predictably a conviction that if we are to continue to impart our understanding of the ancient world to future generations of South African students, if we are to continue to play a role in the Humanities in our universities and in our communities, it will be in the first instance through civilisation courses, at least at the undergraduate level. I recognise that this is anathema to many of you, educated, as indeed was I, in the belief that philology is the one true path in the Classics (perhaps admitting Ancient History as an adjunct), while civilisation courses are the opiate of the masses. Nevertheless, I have come to see that we have arrived at a division of the ways: we can hold fast to our principles, which almost certainly means that we shall go down with the ship, or in the interests of continuity we can change our views, and teach whatever we can to whomever we can as well as we can, in the belief that some access to the ancient world is better than none.

In the discussion that will follow this address, I hope that those who have devised new courses, innovative ways of teaching, will describe their experiences, because it is imperative from now on that as colleagues we share our ideas generously, and co-operate as much as possible between the universities. Every Department, with the exception so far of UCT, has experienced a cut in staffing in the past five years, some, like UFS, UWC and RU, almost to the point of non-viability: a one- or two-person department cannot possibly expect to be creative in coursedevelopment in a whole range of courses. If we combine resources across the country, however, it means that we can all benefit more or less equally from good ideas, and it must be recognised that ultimately, the stronger Classics is nationally, the better each individual academic will be able to justify his or her position, and (what is in the longer term more important) to justify the replacement of him- or herself on resignation or retirement.

The first of my proposals, then, the easiest one that in fact is already in practice in many universities, is that we focus our primary efforts on building up our civilisation courses. I think all of us have done something along these lines already, and so I am not going to discuss this in any more detail, save to stress our need to anticipate the demands of Outcomes-Based-Education (OBE), in terms of the South

7 A figure used by most universities to evaluate viability; it is calculated on the basis of what percentage of time an average student at the relevant level devotes to a course, so that students in first- and second-year courses, who normally take eight semester-courses in the year, count as 0.25 each; students in third-year courses, who normally take four semester courses, count as 0.5 , while graduate students count as 1 each. 
African Quality Assurance (SAQA) catalogue of possible outcomes, and to ensure that we spell out very clearly the realistic and relevant outcomes that will result from our courses. This in fact gives us an advantage that we have not had before, an opportunity to explain up front, in terms that are universally recognised, what are the values of Classics study (even in translation). contribute:

It seems to me that there are three major areas in which we can most readily

1) more even than a History Department, we inculcate a sense of historicity with vast time-scales;

2) our multi-disciplinary courses generate an ability to handle interacting sets of information, which must be interrelated to build up a picture of a multi-faceted society (and our students here also learn to cope with handling analysis when some of the information is irretrievably missing - an invaluable life-skill);

3) our students are encouraged and enabled to draw comparisons between the civilisations of antiquity and their own society-the basis of all the comparative studies currently so popular.

Of course here I am preaching to the converted, for of these aspects we are all well aware. But my point is that we need to be particularly aware of the potential of the move to OBE for our discipline; we need to make an issue of what our courses offer, in terms where comparisons can be made directly with other disciplines. It goes without saying that the additional outcomes that we should be able to achieve in our courses, such as computer and Internet competency, are added advantages.

If we are to direct most of our efforts towards civilisation, then what of our language teaching? Here is where my proposals become more radical. It seems to me that if we all try, on all our campuses, to build up exciting, SAQA-compliant, civilisation courses, then we cannot, given the fixed number of hours in the day, all keep on mounting the full range of ancient language courses. Something has to yield, and a stronger case can be made for making our knowledge available to the larger numbers of students who will register for civilisation courses than for the few, the very few, who come to study Latin and classical Greek. ${ }^{8}$

The arguments for retaining the full complement of the Latin and Greek language majors do not escape me: the most compelling ones are that our postgraduate research students must be able to read their primary research materials in the original if their work is to have any validity; and that if we do not teach the languages, what kind of Classicists are we spawning for the next generation, who will be totally dependent on second hand documentation? and besides, we like teaching the languages, we need to teach them in order to keep up our own language ability, and we tend to undertake to do it "in our own time", sitting up half the night with pleasure. The problem is that all this additional effort needs now to be put into our civilisation courses to ensure that they work, which means that we should not now

In our experience at Natal, Durban, most of our language students are now our research degree candidates needing to fulfil their language requirements; these are highly motivated students who fully recognise the need for language acquisition. 
have spare time unless we cut back on our research, and that is to deny what it is that makes us academics. The compromise that I would propose here for your consideration is that we all try to maintain first year Greek and Latin, and those few Universities where numbers of staff and students are sufficient will probably want to keep second year language studies as well. For the rest, imagine if we could agree to set up a national degree structure; imagine if we all were agreed on the set works for each year; then the second and third year courses could be offered partly at least in distance mode, using e-mail and the Internet for greater immediacy and efficiency.

This would mean that the course work, while agreed upon by us all, would be administered by, say, one University, but the courses would be cross-listed in all our calendars as our own courses, the students would be registered through our own Departments, and we ourselves would meet regularly with our students, perhaps once a week, to discuss their work with them-in short to tutor them. This would mean that our students would have some human contact, someone of whom to ask questions, and their work would be closely monitored; we would all have the pleasure of teaching some part at least of the language courses; but the obligation of meeting with the students five or more times per week would be removed, giving us more time to spend on developing civilisation courses.

I am deliberately not going into precise details of how this could work, because it will need a lot of negotiating, a lot of careful planning, and will need a group of dedicated people to work for a year or more to set it up. It will also require that our various Universities recognise the system, because the Departments putting person-hours into the administration of the courses will clearly need some kind of compensatory funding or other recognition; this would require that the government also recognise the system. At the same time, the Departments "owning" the students must also be able to claim some credit.

What I have just suggested for the languages has potentially also a much wider application. In Classical Civilisation, for instance, especially at the higher levels of the third year of the major, at Honours level, and for course-work Master's papers, we could draw on the expertise of the entire country and so enrich our offerings on every campus. Again, this would require a lot of dedication initially in the setting up, but the tools are now at our disposal for making it work well, in the form of the Internet. Imagine for the sake of argument, since it is my own field, an archaeology course administered from Durban, with all the visual materials accessible on a web-site, and quite a few of the secondary readings accessible at the click of a button. Each campus could potentially offer its specialisations in such a way, and Classics in South Africa could thus become one of the most advanced disciplines, leading the way in South Africa, setting the pattern for making specialist expertise broadly accessible.

There are other possibilities that follow logically upon this. In the commercial world there are many people with narrowly professional degrees who are beginning to recognise the value of a broader humanities education and to regret their lack of it. With the new SAQA system, we could offer a national qualification-some sort of higher educational certificate, leading into a diploma, leading into a course-work 
MA-even just by putting together a syllabus that would offer students insights into the development of deductive argument, for instance; or the meaning of terms such as archaic and classical; they could study works such as Plato's Apology, Homer's Odyssey, Cicero's rhetoric-anything we feel has particularly influenced the subsequent development of thought in the western world. Such a qualification should most certainly be nationally developed, nationally administered, but offered equally on all campuses, again through a combination of Internet access to materials and onthe-spot tutoring by the resident classicists. Apart from anything else, we all could stand to engage a little more extensively in fields other than our own. Such an enterprise would require large-scale thinking and planning, and above all, effective advertising, ideally in consultation with a professional advertising agency. This would require money, and here I think we would need to find sponsorship outside the universities, once the syllabus is designed.

Many other potential developments of this nature can be proposed, but first we need to reach agreement on whether we are prepared to try to work together to this extent, on a national rather than a campus level. If so, then I believe that Classics has the potential once again to become one of the recognised core subjects in a humanities degree, if only because it will be so accessible, so identifiably relevant and of use - and so interesting.

At this point, I want to say something briefly about research resources. Most of us have already been adversely affected in our research by the reduction in library funding on our campuses, and the prospects do not look good for the future. How can we justify requesting the purchase of a book, however "seminal" it may be, for our own personal research projects, when the funds do not even adequately provide for our undergraduate teaching needs? Here again, national or at least provincial rationalisation would seem to be one possible answer, and this would fit in well with the proposals I ventured to put forward earlier. In New Zealand, there used to be an agreement among the Classicists that each one of the. Departments at the four major universities at the time (this goes back to the sixties or earlier) would ensure that it maintained a good specialist library holding in one identified area: The University of Auckland opted for Ancient History, for instance, and the University of Otago, Archaeology. This meant that one could be sure of obtaining most publications by interlibrary loan from somewhere in the country, and one could, when beginning a new study, go physically during the vacation and spend time in the relevant library identifying what was available. I wonder how difficult it would be for us to set up a system like that? We have more Universities, more Departments, more classicists with more fields of expertise: it could result in a very rich resource indeed. This is of course something that could be developed independently of the teaching proposals.

Now I come to what will probably be classed as the real and most outrageous heresy, which I shall introduce with the observation that we are by no means unique in the crisis that we are facing. In its academic effects, for instance, the situation is not unlike the outcomes of Thatcherism in the United Kingdom a decade or so ago. It is only that here, as with everything in South Africa, the new education policies are charged with an underlying awareness of race, culture, advantage and disadvantage, 
haves and have-nots, and they do not seem to have been thoroughly thought through. For me the most significant difference is that in Britain there was always the awareness of the need to save some vestiges of the threatened disciplines through the creation of those much-vilified centres of excellence. Here in South Africa, there is no such central policy at tertiary level, so that each university is acting independently in identifying the "expendable" Departments, and they seem always to be the same ones, Classics among them!

We all hope that Classics will continue to be taught on all our campuses-of course! And we shall all make every effort to ensure the continuity of our discipline-of course! But we must realistically recognise that for a one- or twoperson Department to continue to offer three-year majors in Latin, Greek and Classical Civilisation, as well as probably becoming involved in other teaching within the faculty, is an unrealistic expectation. It would arguably be better to try to persuade the universities and the government to recognise a handful of universities as centres of excellence for Classics, with a view to those Departments' being adequately funded, able to maintain good library holdings and able to offer post-graduate degree supervision in as wide as possible a range of fields. These centres of excellence should even seek to increase their staff numbers in order to broaden their range of specialist offerings; they would then be well equipped to initiate and administer (in collaboration with colleagues elsewhere, as described above) the kind of semidistance courses in languages and classical civilisation to which I referred earlier. The most obvious way of inducing our universities and the government to recognise our plans and to accept the continuing survival of our discipline is to come up with a radical proposal such as this.

If we pursue this proposal, the advantages for the favoured Departments are obvious. What of our colleagues in Departments that do not achieve this coveted status? I believe that, if we are serious about pursuing nationally-defined objectives, we all shall benefit. The smaller Departments will be able via distance-education and the Internet to offer to their students the wider range of courses that can be developed in the larger Departments; their academic staff will have access within the country to improved library holdings, which will have important implications for their research output; they will be able to participate-again via distance-teaching and the Internet-in outside courses, teaching their own specialisation to a larger and more diverse group of students. Because they will not be attempting to do everything for themselves, they will have more time to spend on research, which as well as being of intrinsic importance also has implications for future promotion.

Such a vision of collaborative advantage may sound utopian. It need not be, provided all of us are prepared to put a lot of effort initially into setting things up. If we were to decide to pursue this option, we would need a Grand Plan with a very clear identification of the goals, and of the courses of action appropriate to the pursuit of each one, and we would need to set up a network of sub-committees, each dedicated to working out a separate aspect of the Grand Plan. Above all, we would need a controlling committee directing and overseeing the work in its entirety.

To this point I have focused on the existing concepts of what constitutes 
Classics, and some of the things we can do to ensure the survival and even growth, potentially, of our discipline. But it is not only resting on our shoulders. We have to convince our universities that they have a responsibility to ensure that a discipline is not lost. But we cannot expect them to make a case for Jurassic Park. To our administrations as well as to our students, we must present ourselves as relevant to the twenty-first century world. In fact the new degree structures being foisted upon us with such indecent haste, the programmes, can help us here, because they require a clearer identification of the interrelationships of courses than has ever been provided before.

What does not emerge in the overview above, because it is remarkably difficult to quantify, is the extent to which Classics staff are becoming involved in the mounting of non-Classics programmes. In some cases, as at UNP and UFS, for example, this is part of a formal redeployment of Classics staff; at other institutions it is an informal arrangement whereby Classicists contribute their knowledge and teaching skills to inter- or multi-disciplinary Faculty courses in return for enhancement of the staff-student ratio and, it is understood, increased job-security. Attractive as such enticements may seem, we must nevertheless be careful in determining in which programmes we as classicists will become involved; our decisions must be shaped by expedience. Many of us have already recognised that Classics is a kind of universal donor, able to contribute meaningfully to almost every programme; we must identify those programmes with the greatest potential for being regarded as indispensable, and devise a contribution that will most clearly demonstrate our integral value. This strategy cannot be universally developed, for it will vary in accordance with each university's range of faculties, with the relative strength of existing disciplines, and even with the personalities of those at the head of potentially relevant non-Classics disciplines. For instance, at Natal we have for the past two years contributed a semester course to the first year medical school syllabus-a compulsory course, covering medical etymology, medical history, medical ethics and study skills-that brings us some 200 students each year; I understand that a similar initiative was introduced last year at Pretoria. We have tried, so far without success, to interest our Law Faculty in a similar sort of course for lawyers; I know that other Classics Departments are currently pursuing this latter line with considerably more success.

Such courses (and these are by no means the only possibilities) can enhance perceptions of the practical value of Classics, through their association with "hard" disciplines. Success in such ventures is a major advantage in the battle to persuade universities to accept that a large but mostly non-continuing intake into first year courses justifies maintaining fairly small courses at the more senior levels.

What we must try to avoid is the dissipation of our energies into numerous small-scale contributions to large numbers of diverse programmes that will in all likelihood be competing for the same group of humanities students. This is not to say that we should avoid all contact! We do need to capitalise on the inherently comparative nature of our discipline, to collaborate with colleagues on innovative comparative studies courses-rather than multi-disciplinary courses. Comparative 
studies has in the past had a habit of turning into juxta-positionary studies. We can and we should apply our own disciplinary rigour to provide the fundamental methodology for such courses, provided always that they are potentially truly viable.

With the kind of strategic planning I have briefly outlined, in yet another way we extend our potential if we can agree to national collaboration. First, we must share our ideas, so that all the medical courses, all the law courses, are equally perceived as "good". Then we can put pressure, for instance, on law faculties in other universities, through law faculties elsewhere already using a Classics course, to consider including such a course in their own programme - and this can even be partially distance- and Internet-administered, as with language and civilisation courses.

There are several key elements in what may seem a disparate series of proposals here:

1. National cooperation-in a practical and real sense-towards agreed goals.

2. National establishment of quality and expectations, as a defence against accusations of lowering standards.

3. Using the resources now available to accomplish these aims.

We cannot afford to have even a single Department in the country perceived as weak, because that will potentially lower the perception of the value of Classics elsewhere. A one- or two-person Department is a weak Department in the making not because of any deficiency in the staff of such Departments: on the contrary, these are the real heroines and heroes of our guild, who willingly shoulder huge teaching loads year after year in order to try to maintain the whole range of courses at all levels. But we cannot afford to have one or two larger Departments forging ahead with new developments and leaving these smaller ones behind-especially not when the Internet provides us with the opportunity to work nationally as one big virtual Department. In this way, even those universities that do not want to recognise the value of their Classics Departments, that do not want to see their potential, will be forced to acknowledge that Classics is here to stay, and that like a pruned tree, it will grow with renewed vigour, better and more fruitful than before.

We should look back to the privileged position in education that our discipline used to enjoy. We should especially analyse why we were regarded for so long as a core discipline. But we must also recognise that the world has changed meanwhile, and continues to change ever more rapidly, so that we shall need regularly to redefine our relevance accordingly. That is, we need, through all the means at our disposal, with all our innovative ingenuity, to find convincing ways of reclaiming our place at the centre of things for the future, and of ensuring our continuity and that of our discipline. Respice! Inspice! Prospice! 